\title{
Recent Progress on the Evolution of Pourbaix Sensors: Molecular Logic Gates for Protons and Oxidants
}

\author{
David C. Magri $(1)$ \\ Department of Chemistry, Faculty of Science, University of Malta, MSD 2080 Msida, Malta; \\ david.magri@um.edu.mt; Tel.: +356-2340-2276
}

Received: 8 October 2018; Accepted: 29 October 2018; Published: 31 October 2018

\begin{abstract}
Recent progress in the area of molecular logic, in particular molecules capable of sensing for acidity and oxidizability, are gathered together in this short review. Originally proposed as AND logic gates that provide a high fluorescence output when simultaneously protonated and oxidized, the concept has been extended from two-input to three-input variants and to include molecules that function as INHIBIT logic gates. Photochemical concepts such as photoinduced electron transfer (PET) and internal charge transfer (ICT) are exploited as favorite design concepts. This review highlights the evolution of Pourbaix sensors with anthracene, pyrazoline, and naphthalimide fluorophores. Future applications abound in various disciplines from corrosion science, material science, geochemistry to cell imaging.
\end{abstract}

Keywords: molecular logic gate; photoinduced electron transfer; internal charge transfer; fluorescence; luminescence; molecular sensor; redox indicator; $\mathrm{pH}$ indicator

\section{Introduction}

The 6th International Conference on Molecular Sensors and Molecular Logic Gates (MSMLG) was held in Dalian, China on June 4 and 5 [1]. The conference presentations were dominated by work on fluorescent molecular sensors for metal cations, and to a lesser extent, on the detection of anions and organic molecules, in solution, luminescent materials, and cell imaging applications [2]. Presentations on the recent developments of molecular logic gates [3] were underrepresented as many in the field did not make the pilgrimage to Dalian. Nonetheless, the conference was an overwhelming success with 193 registered participants [1].

This year, 2018, marks the 25th anniversary since the publication of the first book on fluorescent chemosensors as a symposium series [4]. As comes with technological advancements, it is usually not without criticism and controversy. The analytical chemistry community, as pointed out by Wolfbeis, consider chemical sensors as miniaturized analytical devices that can deliver real-time and online information on the presence of specific compounds or ions in complex samples [5]. In 1997 Desvergne and Czarnik published Fluorescent Chemosensors of Ion and Molecule Recognition and provided a less restrictive definition from an organic chemist's perspective such that a continuous time-measure parameter was not a necessary consideration [6]. A positive consequence has been the creative pursuit of libraries of new molecules for a range of analyte targets. This year also marks the silver anniversary of de Silva's digital leap from fluorescent chemical sensing for a single analyte to multi-input detection with the introduction in 1993 of the cross-fertilization of Boolean algebra with the organic chemistry realm [7]. The current testament in the field of information processing with molecules Molecular Logic-based Computation by de Silva celebrates its 5th birthday [8]. This year is also the 5th anniversary of the concept of 'Pourbaix sensors', the thematic topic of this article [9,10]. 


\section{Background}

Marcel Pourbaix was a Belgian electrochemist with a particular interest in understanding corrosion processes. Regarded as a pioneer in the field, he is credited for developing and popularizing potential-pH diagrams constructed from the Nernst equation [11]. These two-dimensional figures display in a pictorial manner horizontal, vertical, and diagonal lines, which correspond to the thermodynamic boundary conditions for the various states of an element. The areas within the predicted zones reveal under what conditions an element will dissolve, precipitate, corrode, or be immune to corrosion by passivation of an oxide layer.

In the industrialized world, iron is symbolic of the various states of an element in the natural environment. Iron(III) is readily soluble species in water below $\mathrm{pH} 4$ under oxidizing conditions of $0.8-1.6 \mathrm{~V}$. Iron(II) is also a water soluble species, but over a broader range between $\mathrm{pH} 0-8$. At $\mathrm{pH}$ above 8 , iron tends to exist as either an oxide or in elemental state. Iron is the core element of steel.

A large amount of capital expenditure, amounting to billions of euros, is on corrosion-prone infrastructure such as merchant vessels, ocean wind turbines, expansion bridges, and military vehicles. There is also the additional economic cost of routine maintenance. Tremendous effort goes into the protection and prevention of corrosion using paints, protective coatings, and sacrificial electrodes. A method for the early detection of corrosion of ferrous and other metallic materials, when damage is minimal, could have tremendous economic savings. The early detection of corrosion before it is visible to the naked eye, using fluorescent molecules, is a viable approach.

The relationship between acidity and redox chemistry is also of paramount importance to medicine and cell biology. Substantial research has documented that many forms of cancer have high levels of $\mathrm{H}^{+}$and metal ions, notably $\mathrm{Fe}^{3+}$, a common biological oxidant [12]. Many blood disorders result from an imbalance of high $\mathrm{H}^{+}$levels and elevated $\mathrm{Fe}^{3+}$ levels released from haemoglobin or the enzyme transferrin [13]. Research is on-going to develop acid and redox-responsive micelles as intracellular drug delivery systems [14]. However, despite the known interdependence of acidity and redox chemistry in biology, there are no fluorescent probes commercially available for the simultaneous detection of acidity and oxidizability in living cells [15].

This review provides an overview of the current state in the evolution of Pourbaix sensors, fluorescent molecular logic gates for $\mathrm{pH}$ (acidity) and $\mathrm{pE}$ (redox potential) $[9,10]$. Researchers within the chemosensor community with an interest in the design, synthesis, and function of molecular sensors and molecular logic gates are the target audience. Previous articles have highlighted aspects of design concepts, the mechanisms of operation (photoinduced electron transfer (PET) and internal charge transfer (ICT)) [16-18] and some envisioned applications of this new class of chemosensor [19,20]. Pourbaix sensors could, in principle, have applications in various disciplines from living cell imaging, corrosion detection, water quality, medical diagnostics, and environmental analysis. Although this new field is currently at the proof-of-concept stage, we are already considering pragmatic uses. This paper highlights many of our recent advances reported at the 2018 MSMLG conference as well as our latest published results.

\section{Results}

Molecules 1 and 2 function as fluorescent AND logic gates $[9,10]$. They share the same design characteristics according to a fluorophore-spacer 1 -receptor-spacer ${ }_{2}$-electron donor format (Figure 1). These molecules are PET-based devices with two methylene spacers, a tertiary amine receptor and an electron donor, tetrathiafulvalene and ferrocene, for $\mathbf{1}$ and $\mathbf{2}$, respectively. On protonation of the amine and oxidation of the electron donor, $\mathbf{1}$ and $\mathbf{2}$ emit a blue fluorescence visible to the naked eye. A 'turn-on' response of five-fold was observed for both in acetonitrile, and in methanol for 2 . The original prototype $\mathbf{1}$ [10] was observed to undergo fluorescence quenching beyond stoichiometric $\mathrm{Fe}^{3+}$ levels resulting in an 'off-on-off' behavior. Prototype 2 alleviated this issue as higher $\mathrm{Fe}^{3+}$ levels did not cause a drastic fluorescence quenching. A predecessor by Yan 3 connects the anthracene and 
ferrocene modules by a 2,3-diaza-1,3-butadiene bridge and uses trifluoroacetic acid and $\mathrm{Ce}^{4+}$ as the proton source and oxidant, respectively, in THF [21].
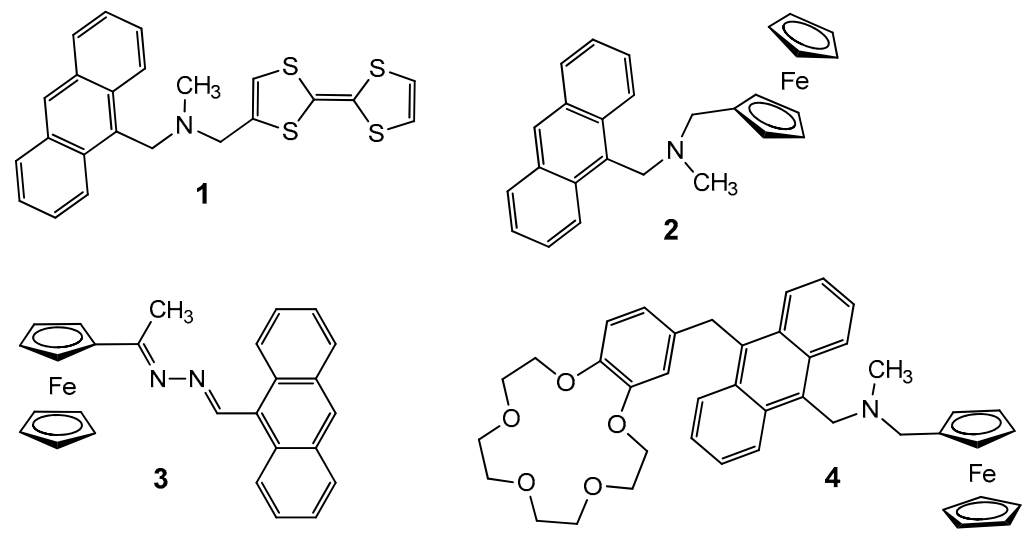

Figure 1. Fluorescent two-input AND logic gates 1-4 for protons and redox potential with an anthracene fluorophore.

The progression from two-input 2 to a three-input AND logic gate 4 required additional spacer and

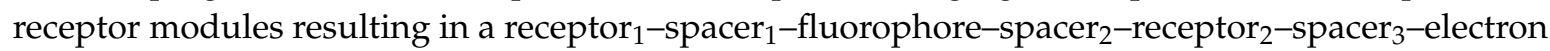
donor format [22]. The concept of detecting for a trio (or more) of analytes by a fluorescent response was proposed as a 'lab-on-a-molecule' [23]. Enhanced fluorescence is emitted by 4 in the presence of 'high' $\mathrm{Na}^{+}, \mathrm{H}^{+}$and $\mathrm{Fe}^{3+}$ levels with an $\Phi_{\mathrm{f}}$ of 0.072 in methanol. The benzo-15-crown-5 ether binds $\mathrm{Na}^{+}$, the tertiary amine $\mathrm{H}^{+}$and the ferrocene is oxidized by $\mathrm{Fe}^{3+}$. With reference to 2, PET from the crown receptor to the anthracene fluorophore is a third PET deactivation pathway. The higher $\Phi_{\mathrm{f}}$ is due to the $\mathrm{Na}^{+}$-bound crown electrostatically retarding the PET process from the excited anthracene to the ferrocenium unit [24]. High $\mathrm{Na}^{+}, \mathrm{H}^{+}$and $\mathrm{Fe}^{3+}$ levels are all associated with steel corrosion thus 4 is a 'lab-on-a-molecule' that could in principle provide an early warning to engineers inspecting the integrity of steel structures in the sea.

Pourbaix sensors 5 and $\mathbf{6}$ are our first examples with a naphthalimide fluorophore (Figure 2) [25,26]. An example by Gan and co-workers has much the same hallmarks of 6 , but with a piperazine bridge and carboxyferrocene connected at the 4-amino terminus and an oxyalkyl chain at the imide position [27]. It was tested under acidic and oxidizing conditions, but only as separate inputs, so the synergetic effect from both inputs was not captured in the fluorescence output. Compared to the anthracene prototypes 1-4, the naphthalimide prototypes 5-8 have longer emission maxima and are solubility in aqueous methanol. Molecule $\mathbf{6}$ is designed in the same manner as $\mathbf{1}$ and $\mathbf{2}$ with a fluorophore-spacer 1 -receptor-spacer ${ }_{2}$-electron donor format. The emission peak maximum of $\mathbf{6}$ is observed at $526 \mathrm{~nm}$ with a four-fold switching enhancement and an $\Phi_{\mathrm{f}}$ of 0.04 which is double the emission of the anthracene models $\mathbf{1}$ and $\mathbf{2}$.

Rearrangement of the modules, as exemplified by $\mathbf{5}$, in the order 'electron-donor-spacer 1 -fluorophore-spacer ${ }_{2}$-receptor' improved device performance to yield a 16-fold switching enhancement and a $\Phi_{\mathrm{f}}$ of 0.09 . A sister molecule with piperazine instead of methylpiperazine as the proton receptor switches 6-fold with an $\Phi_{\mathrm{f}}$ of 0.06 [28]. The shorter distance for charge transfer between the ferrocene and the excited state fluorophore is a favorable factor as is the $\pi \pi^{*}$ ICT state, which causes a dipole moment in the photoexcited state [29]. Consequently, charge separation within the excited naphthalimide fluorophore yields a negative charge build-up at the imide carbonyl end and a positive charge build up at the 4-amino end [30]. 

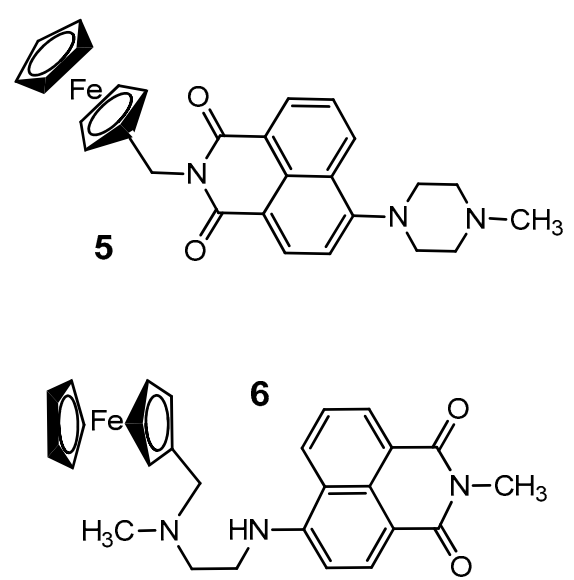


Figure 2. Fluorescent two-input AND logic gates 5-7 for $\mathrm{pH}$ and redox potential with a naphthalimide fluorophore and two-input PASS 0 logic gate 8.

The 'electron-donor-spacer 1 -fluorophore-spacer ${ }_{2}$-receptor' arrangement was further tested by designing two pairs of regioisomers as exemplified by 7 and 8 [31]. We observed that 7 functions as a $\mathrm{H}^{+}, \mathrm{Fe}^{3+}$-driven AND logic gate with a 10-fold fluorescence enhancement and a $\Phi_{\mathrm{f}}$ of 0.03 in 1:1 $(v / v)$ methanol/water. Regioisomer 8 did not response to $\mathrm{H}^{+}$and $\mathrm{Fe}^{3+}$ inputs with an elevated fluorescence signal. Rather, 8 functioned as a $\mathrm{H}^{+}, \mathrm{Fe}^{3+}$-driven PASS 0 logic gate. Femtosecond transient absorption studies of $\mathbf{7}$ and $\mathbf{8}$ clearly demonstrated that the photophysical response after excitation is significantly different: $\mathbf{7}$ decays on the picoseconds timescale while $\mathbf{8}$ decays on the nanosecond timescale. The excited state electric field effect is the culprit. The positive charge build-up at the 4-amino terminus contributes to accelerate an electron transfer from the fluorophore to the ferrocenium unit across the positive electric field. Consequently, fluorescence is not observed from 8 under oxidizing (and protonated) conditions. This exception to the general principles predicted by the Weller equation introduces a new paradigm for regulating logic functions in fluorescent molecules.

Zhang has reported a novel ferrocenyl-naphthalimide in water reminiscent to a Pourbaix sensor [32]. However, the adjacent thiosulfoxide prevents the piperazine nitrogen atom from acting as a proton receptor. Rather the molecular device is presented as a multi-channel dual probe for $\mathrm{Cu}^{2+}$ or $\mathrm{Hg}^{2+}$. The yellow solution turns colorless in the presence of either metal cation, and simultaneously results in a fluorescent 'turn-on' response with $\mathrm{Cu}^{2+}$ with a $\Phi_{\mathrm{f}}$ of 0.59 and a fluorescent 'turn-off' response with $\mathrm{Hg}^{2+}$ in 7:3 (v/v) acetonitrile/water. The molecule was used in intracellular fluorescent imaging studies and found to be non-toxic and to give a promising response on $\mathrm{Cu}^{2+}$ detection.

A concern when analysing heavy metal ions in water is the formation of a metal salt precipitate at higher $\mathrm{pH}$ levels [11]. A strategy for ensuring precipitation does not occur during analysis in water is to work at high proton concentrations of say $\mathrm{pH} 2$ [33]. Example 9 was designed as an $\mathrm{H}^{+}$-driven fluorescent $\mathrm{pH}$ indicator for use in water (Figure 3) [34]. As the molecule emits in the UV and blue visible region of the electromagnetic spectrum, it is susceptible to quenching by an inner filter effect by $\mathrm{Fe}^{3+}$. A line break was not observed in the Job's plot analysis ruling a metal-ligand interaction. Probe 9 has a $\mathrm{pK}_{\mathrm{a}}$ of 7.9 and a fluorescent quantum yield of 0.62 in water. Addition of $11 \mathrm{mM} \mathrm{Fe} \mathrm{F}^{3+}$ at $\mathrm{pH} 3$ results in near complete quenching of the fluorescent. The fluorescent output in response to $\mathrm{H}^{+}$and $\mathrm{Fe}^{3+}$ is an example of two-input INHIBIT logic and provides a way of avoiding hydrolysis, thus ensuring a more reliable measurement. 
<smiles>CN(CCS(=O)(=O)O)Cc1c2ccccc2cc2ccccc12</smiles>

9
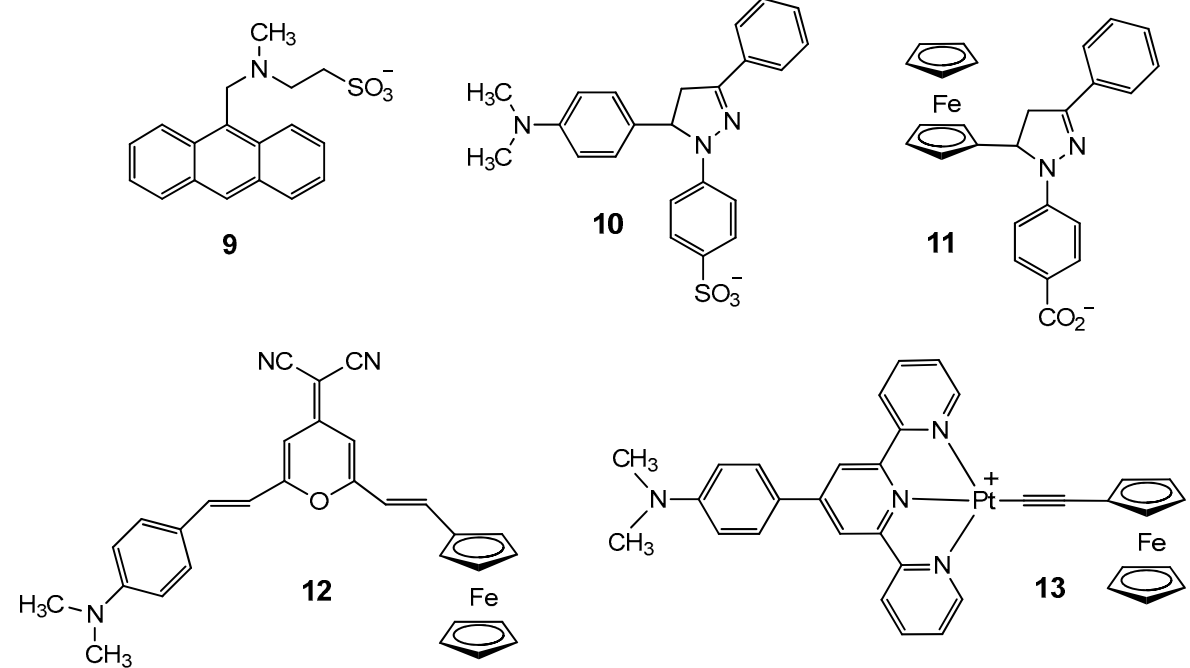

Figure 3. Fluorescent logic gates $\mathbf{9}, \mathbf{1 1}$ and $\mathbf{1 3}$ with INHIBIT logic functions and $\mathbf{1 0}$ with ternary 'off-on-off' logic functions. Logic gate 12 was not fully analyzed.

Triarylpyrazolines have been in the molecular engineer's toolkit for some time as fluorescent $\mathrm{pH}$ indicators [35], metal ion chemosensors [36-38], and cell imaging probes [39]. The rigid heterocyclic framework and facile aryl-substitution allows for fine-tuning of the photophysical properties [40]. Pyrazoline-based chemosensors are usually designed with a PET process originating from a moiety at the 5-position and an ICT state modulated by the choice of aryl substituents on the phenyl rings at the 1and 3-positions. Quenching of the fluorescent occurs at $10^{-1} \mathrm{M}$ acid due to protonation of the N2 atom. We capitalized on this known deactivation pathway to demonstrate $\mathrm{H}^{+}$-driven ternary 'off-on-off' logic with 10 [41] and $\mathrm{H}^{+}, \mathrm{Fe}^{3+}$-driven INHIBIT logic with 11 [42] (Figure 3). The latter logic result comes from an enhanced fluorescent signal at low proton and high oxidant threshold levels. While the $\mathrm{H}^{+}$-driven indicator $\mathbf{1 0}$ has a fluorescence quantum yield of 0.38 and a fluorescence enhancement of 20 [41], the redox-enabled pH-disabled logic gate $\mathbf{1 1}$ registers a remarkable 120-fold fluorescent enhancement, but with only 0.012 quantum yield output [42] in aqueous methanol. Experiments with stronger oxidants and inert electrodes should enhance the fluorescence output.

Zhu reports a dicyanomethylene-4H-pyran 12 with conjugated dimethylaniline and ferrocene moieties that in THF emits at $610 \mathrm{~nm}$ on addition of one equivalent of $\mathrm{Fe}^{3+}$ [43]. It is suggested that the fluorescence is regulated by both PET and ICT mechanisms. The study includes cyclic voltammetry and time-resolved fluorescence measurements in addition to DFT calculations. Examined as a redox-fluorescent switch, the fluorescence enhancement exceeds 100-fold. Regrettably, though, the authors do not report the effect of acid on the fluorescence modulation, and consequently, the built-in two-input logic gate features.

$\mathrm{A} \mathrm{H}^{+}, \mathrm{Fe}^{3+}$ driven INHIBIT logic gate $\mathbf{1 3}$ by $\mathrm{Wu}$ uses absorbance at $405 \mathrm{~nm}$ in acetonitrile as the output channel [44]. A modular design is evident according to an 'electron-donor-fluorophore-spacer-receptor' construction. The prototype consists of a dimethylaniline moiety (receptor) attached to a terpyridyl Pt complex (fluorophore) linked to a ferrocenyl acetylide (electron donor). A virtual spacer via the carbon-carbon bond between the dimethylaniline and terpyridyl units keeps these two modules electronically decoupled. Photoinduced electron transfer from the dimethylaniline unit to the ferrocenyl acetylide regulates the emission output.

A three-input combinatorial INHIBIT logic gate $\mathbf{1 4}$ was demonstrated by James and co-workers using a ferrocene-naphthalimide-boronic acid conjugate (Figure 4) [45]. A high fluorescence output was observed in the presence of 'high' $\mathrm{Fe}^{3+}$, 'low' sodium L-ascorbate and 'low' $\mathrm{F}^{-}$. Minimal fluorescence output is observed with no added chemical inputs on excitation at $403 \mathrm{~nm}$ in THF. One equivalent of $\mathrm{Fe}^{3+}$ is sufficient to oxidize the ferrocene moiety and to cause a 100-plus fluorescent enhancement 
centred at $512 \mathrm{~nm}$. Fluoride acts as a nucleophile to form a tetrahedral boronate anion, which causes a delayed fluorescence enhancement, possibly due to an ion pair interaction between $\mathrm{Fe}^{3+}$ and $\mathrm{F}^{-}$.
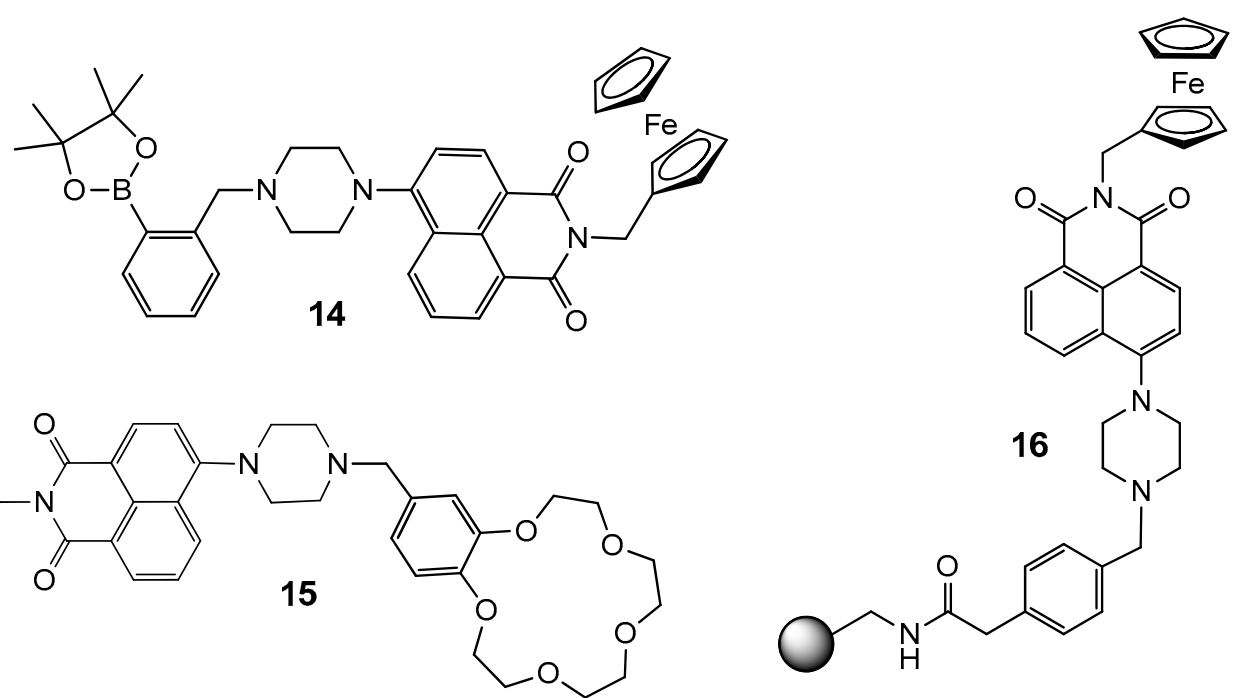

Figure 4. Fluorescent logic gates $\mathbf{1 4}$ and $\mathbf{1 5}$ with more complex logic functions and logic tagged polymeric bead 16.

The molecule $\mathbf{1 5}$ is a logic gate array equivalent to wiring together three-input AND, three-input INHIBIT and two-input OR logic gates [46]. On first inspection, the molecular device appears as a three-input logic gate driven by $\mathrm{Na}^{+}, \mathrm{H}^{+}$and $\mathrm{Fe}^{3+}$ as with 4 . A bright green fluorescence with an $\Phi_{\mathrm{f}}$ of 0.0193 is observed in the presence of 'high' levels of all three analytes. However, a green fluorescence output is also observed in the presence of 'high' $\mathrm{H}^{+}$and $\mathrm{Fe}^{3+}$ and 'low' $\mathrm{Na}^{+}$levels. Despite the favourable photogenerated electric field effect at the 4-amino position of the excited naphthalimide fluorophore [29], the greater separation distance between the crown ether receptor and the fluorophore is not enough to retard PET. The net result is that of eight possible truth table entries, two combinations of inputs yield a green emission output.

Many of the logic gates reviewed are soluble in an organic solvent, or require a co-solvent for solubility in water. Hence, the attachment of organic molecules onto solid supports is a convenient way of circumventing the issue of insolubility in water. Attachment onto a solid support opens up many applications too, such as molecular computational identification (MCID), the labelling and identification of small objects [47]. PASS 1 and YES logic tags with anthracene and 4-aminonaphthalimindes have recently featured on polyethyleneglycol-polystyrene (Tentagel) beads and silica particles [48]. Our first Pourbaix sensor on a polymer bead 16 retains the modular skeleton of 5 [49], but is extended with a benzoic acid moiety, which functions as a linker unit allowing for secure fastening of the molecular logic gate to the amino-terminated beads by peptide coupling chemistry [50]. The millimeter-sized sensor glows fluorescent green in the presence of $200 \mu \mathrm{M} \mathrm{H}^{+}$and $20 \mu \mathrm{M} \mathrm{Fe}{ }^{3+}$, which can be reversibly switched to the initial 'off' state on addition of hydroxide and EDTA. The beads were observed to be robust and stable when stored in methanol over numerous months, which bodes well for real-time continuous measurements.

\section{Conclusions}

Chemosensors that function as molecular logic gates responsive to $\mathrm{pH}$ and redox potential could have practical applications in corrosion science, medical diagnostics, catalysis, environmental monitoring, and cell biology [19,20]. With the proof-of-concept now established, one obvious direction is the testing of Pourbaix sensors in living cells. Many of the presented examples, notably with a naphthalimide fluorophore, are naturally suited as fluorescent cellular imaging probes and as 
potential cancer therapy agents [51,52]. Other avenues to consider are the development of solid-bound fluorescent Pourbaix sensors [49] and luminescent-based nanomaterial platforms (e.g., carbon quantum dot sensors [53,54]).

For those interested in a challenge, current limitations to be addressed include: (1) enhanced aqueous solubility without the need for a co-solvent; (2) improved fluorescent quantum yields $\left(\Phi_{\mathrm{f}} \geq 0.1\right)$; (3) longer emission wavelengths towards the infra-red region; and (4) prototypes responsive to various oxidants.

To conclude, the 7th International Conference on Molecular Sensors and Molecular Logic Gates (MSMLG) will be held in 2020 in Rio, Nevada, America. Our host will be Anthony Czarnik.

Funding: This research received no significant external funding.

Acknowledgments: The University of Malta, the Embassy of France to Malta, CNRS (Centre national de la recherché sciéntifique) and MCST (Malta Council for Science and Technology) are acknowledged for financial support. Gratitude is extended to colleagues at the Université de Bordeaux and CNRS, and AGH University of Science and Technology for fruitful collaborations.

Conflicts of Interest: The author declares no conflict of interest.

\section{References}

1. 6th International Conference on Molecular Sensors and Molecular Logic Gates. Available online: http: //msmlg2018.dlut.edu.cn/meeting/index_en.asp?id=2636 (accessed on 5 September 2018).

2. Wu, D.; Sedgwick, A.C.; Gunnlaugsson, T.; Akkaya, E.U.; Yoon, J.; James, T.D. Fluorescent chemosensors: The past, present and future. Chem. Soc. Rev. 2017, 46, 7105-7123. [CrossRef] [PubMed]

3. Erbas-Cakmak, S.; Gunnlaugsson, T.; Kolemen, S.; James, T.D.; Sedgwick, A.C.; Yoon, J.; Akkaya, E.U. Molecular logic gates: The past, present and future. Chem. Soc. Rev. 2018, 47, 2228-2248. [CrossRef] [PubMed]

4. Czarnik, A.W. Fluorescent Chemosensors for Ion and Molecule Recognition; American Chemical Company: Washington, DC, USA, 1993.

5. Wolfbeis, O.S. Probes, sensors, and labels: Why is real progress slow? Angew. Chem. Int. Ed. 2013, 52, 9864-9865. [CrossRef] [PubMed]

6. Desvergne, J.P.; Czarnik, A.W. Fluorescent Chemosensors of Ion and Molecule Recognition; Springer Science \& Business Media: Dordrecht, The Netherlands, 1997.

7. de Silva, A.P.; Gunaratne, H.Q.N.; McCoy, C.P. A molecular photoionic AND gated based on fluorescence signaling. Nature 1993, 364, 42-43. [CrossRef]

8. de Silva, A.P. Molecular Logic-based Computation; The Royal Society of Chemistry: Cambridge, UK, 2013.

9. Farrugia, T.J.; Magri, D.C. 'Pourbaix sensors': A new class of fluorescent pE-pH molecular AND logic gates based on photoinduced electron transfer. New J. Chem. 2013, 37, 148-151. [CrossRef]

10. Magri, D.C. A fluorescent AND logic gate driven by electrons and protons. New J. Chem. 2009, 33, 457-461. [CrossRef]

11. Pourbaix, M. Atlas of Electrochemical Equilibria in Aqueous Solutions; Pergamon Press: Oxford, UK, 1966.

12. Huang, X. Iron overload and its association with cancer risk in humans: Evidence for iron as a carcinogenic metal. Mutat. Res. 2003, 533, 153-171. [CrossRef] [PubMed]

13. Aisen, P.; Leibman, A.; Zweier, J. Stoichiometric and site characteristics of the binding of iron to human transferrin. J. Biol. Chem. 1978, 253, 1930-1937. [PubMed]

14. Erbas-Cakmak, S.; Pir Cakmak, F.; Demirel Topel, S.; Bilal Uya, T.; Akkaya, E.U. Selective photosensitization through an AND logic response: Optimization of the $\mathrm{pH}$ and glutathione response of activatable photosensitizers. Chem. Commun. 2015, 51, 12258-12261. [CrossRef] [PubMed]

15. Johnson, I.; Spence, M.T.Z. The Molecular Probes Handbook: A Guide to Fluorescent Probes and Labeling Technologies, 11th ed.; Life Technologies Corporation: Carlsbad, CA, USA, 2010.

16. de Silva, A.P.; Moody, T.S.; Wright, G.D. Fluorescent PET (Photoinduced Electron Transfer) sensors as potent analytical tools. Analyst 2009, 134, 2385-2393. [CrossRef] [PubMed]

17. Magri, D.C. Photoinduced electron transfer as a design concept for luminescent redox indicators. Analyst 2015, 140, 7487-7495. [CrossRef] [PubMed] 
18. Magri, D.C. Correction: Photoinduced electron transfer as a design concept for luminescent redox indicators. Analyst 2017, 142, 676. [CrossRef] [PubMed]

19. Magri, D.C. 'Pourbaix sensors': Fluorescent molecular logic gates for $\mathrm{pE}$ and $\mathrm{pH}$. Supramol. Chem. 2017, 20, 741-747. [CrossRef]

20. Magri, D.C.; Johnson, A.D.; Spiteri, J.C. Fluorescent photoinduced electron transfer (PET) logic gates for acidity $(\mathrm{pH})$ and redox potential (pE). J. Fluoresc. 2017, 27, 551-559. [CrossRef] [PubMed]

21. Fang, C.J.; Li, C.Y.; Fu, X.F.; Yue, Y.F.; Yan, C.H. Redox-active fluorescent molecular switch to realize AND logic function. Chinese J. Inorg. Chem. 2008, 24, 1832-1836.

22. Magri, D.C.; Camilleri Fava, M.; Mallia, C.J. A sodium-enabled 'Pourbaix sensor': A three-input AND logic gate as a 'lab-on-a-molecule' for monitoring $\mathrm{Na}^{+}, \mathrm{pH}$ and $\mathrm{pE}$. Chem. Commun. 2014, 50, 1009-1011. [CrossRef] [PubMed]

23. Magri, D.C.; Brown, G.J.; McClean, G.D.; de Silva, A.P. Communicating chemical congregation: A molecular AND logic gate with three chemical inputs as a "Lab-on-a-Molecule" prototype. J. Am. Chem. Soc. 2006, 128, 4950-4951. [CrossRef] [PubMed]

24. Daly, B.; Ling, J.; de Silva, A.P. Information gathering and processing with fluorescent molecules. Front. Chem. Sci. Eng. 2014, 8, 240-251. [CrossRef]

25. Spiteri, J.C.; Schembri, J.S.; Magri, D.C. A naphthalimide-based 'Pourbaix sensor': A redox and pH driven AND logic gate with photoinduced electron transfer and internal charge transfer mechanisms. New J. Chem. 2015, 39, 3349-3352. [CrossRef]

26. Johnson, A.D.; Paterson, K.A.; Spiteri, J.C.; Denisov, S.A.; Jonusauskas, G.; Tron, A.; McClenaghan, N.D.; Magri, D.C. Water-soluble naphthalimide-based 'Pourbaix sensors': $\mathrm{pH}$ and redox-activated fluorescent AND logic gates based on photoinduced electron transfer. New J. Chem. 2016, 40, 9917-9922. [CrossRef]

27. Gan, J.; Tian, H.; Wang, Z.; Chen, K.; Hill, J.; Lane, P.A.; Rahn, M.D.; Fox, A.M.; Bradley, D.D.C. Synthesis and luminescence properties of novel ferrocene-naphthalimides dyads. J. Organomet. Chem. 2002, 645, 168-175. [CrossRef]

28. Spiteri, J.C.; Johnson, A.D.; Denisov, S.A.; Jonusauskas, G.; McClenaghan, N.D.; Magri, D.C. A fluorescent AND logic gate based on a ferrocene-naphthalimide-piperazine format responsive to acidity and oxidizability. Dyes Pigm. 2018, 157, 278-283. [CrossRef]

29. de Silva, A.P.; Gunaratne, H.Q.N.; Habib-Jiwan, J.L.; McCoy, C.P.; Rice, T.E.; Soumillion, J.P. New fluorescent model compounds for the study of photoinduced electron transfer: The influence of a molecular field effect in the excited state. Angew. Chem. Ed. Int. 1995, 107, 1728-1731. [CrossRef]

30. Panchenko, P.A.; Fedorova, O.A.; Fedorov, Y.V. Fluorescent and colorimetric chemosensors for cations based on 1, 8-naphthalimide derivatives: Design principles and optical signaling mechanisms. Russ. Chem. Rev. 2014, 83, 155-182. [CrossRef]

31. Spiteri, J.C.; Denisov, S.A.; Jonusauskas, G.; Klejna, S.; Szaciłowski, K.; McClenaghan, N.D.; Magri, D.C. Molecular engineering of logic gate types by module rearrangement in 'Pourbaix sensors': The effect of excited-state electric fields. Org. Biomol. Chem. 2018, 16, 6159-6201. [CrossRef] [PubMed]

32. Dong, J.; Hu, J.; Baigude, H.; Zhang, H. A novel ferrocenyl-naphthalimide as a multichannel probe for the detection of $\mathrm{Cu}(\mathrm{II})$ and $\mathrm{Hg}(\mathrm{II})$ in aqueous media and living cells. Dalton Trans. 2018, 47, 314-322. [CrossRef] [PubMed]

33. Czarnik, A.W. Chemical communication in water using fluorescent chemosensors. Acc. Chem. Res. 1994, 27, 302-308. [CrossRef]

34. Cardona, M.A.; Mallia, C.J.; Baisch, U.; Magri, D.C. Water-soluble amino(ethanesulfonate) and [bis(ethanesulfonate)] anthracenes as fluorescent photoinduced electron transfer (PET) pH indicators and $\mathrm{Fe}^{3+}$ chemosensors. RSC Adv. 2016, 6, 3783-3791. [CrossRef]

35. de Silva, A.P.; Gunaratne, H.Q.N.; Mark Lynch, P.L.; Patty, A.J.; Spence, G.L. Luminescence and charge transfer. Part 3. The use of chromophores with ICT (Internal Charge Transfer) excited states in the construction of fluorescent PET (Photoinduced Electron Transfer) $\mathrm{pH}$ sensors and related absorption $\mathrm{pH}$ sensors with aminoalkyl side chains. J. Chem. Soc. Perkin Trans. 2 1993, 1611-1616. [CrossRef]

36. Bricks, J.L.; Kovalchuk, A.; Trieflinger, C.; Nofz, M.; Bushcel, M.; Tolmachev, A.I.; Daub, J.; Rurack, K.

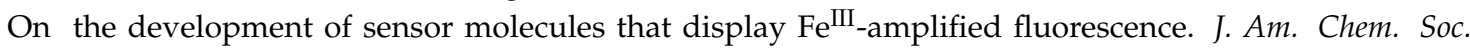
2005, 127, 13522-13529. [CrossRef] [PubMed] 
37. de Silva, A.P.; Gunaratne, H.Q.N.; Gunnlaugsson, T.; Nieuwenhuizen, M.T. Fluorescent switches with high selectivity towards sodium ions: Correlation of ion-induced conformation switching with fluorescence function. Chem. Commun. 1996, 16, 1967-1968. [CrossRef]

38. de Silva, A.P.; Gunaratne, H.Q.N. Fluorescent PET (Photoinduced Electron Transfer) sensors selective for submicromolar calcium with quantitatively predictable spectral and ion-binding properties. Chem. Commun. 1990, 2, 186-188. [CrossRef]

39. Morgan, M.T.; Bagchi, P.; Fahrni, C.J. Designed to dissolve: Suppression of colloidal aggregation of $\mathrm{Cu}(\mathrm{I})$-selective fluorescent probes in aqueous buffer and in-gel detection of a metallochaperone. J. Am. Chem. Soc. 2011, 133, 15906-15909. [CrossRef] [PubMed]

40. Rurack, K.; Resch-Genger, U. Rigidization, preorientation and electronic decoupling-The 'magic triangle' for the design of highly efficient fluorescent sensors and switches. Chem. Soc. Rev. 2002, 31, 116-127. [CrossRef]

41. Zammit, R.; Pappova, M.; Zammit, E.; Gabarretta, J.; Magri, D.C. 1,3,5-Triarylpyrazolines-pH-driven off-on-off molecular logic devices based on a "receptor ${ }_{1}$-fluorophore-spacer-receptor 2 " format with internal charge transfer (ICT) and photoinduced electron transfer (PET) mechanisms. Can. J. Chem. 2015, 93, 199-206. [CrossRef]

42. Scerri, G.J.; Cini, M.; Schembri, J.S.; da Costa, P.F.; Johnson, A.D.; Magri, D.C. Redox-enabled, pH-disabled pyrazoline-ferrocene INHIBIT logic gates. ChemPhysChem 2017, 18, 1742-1745. [CrossRef] [PubMed]

43. Yang, J.; Li, M.; Kang, L.; Zhu, W. A Luminescence molecular switch via modulation of PET and ICT processes in DCM system. Sci. China Chem. 2017, 60, 607-613. [CrossRef]

44. Liu, X.Y.; Han, X.; Zhang, L.P.; Tung, C.H.; Wu, L.Z. Molecular logic circuit based on a multi-state mononuclearplatinum(II) terpyridyl complex. Phys. Chem. Chem. Phys. 2010, 12, 13026-13033. [CrossRef] [PubMed]

45. Li, M.; Guo, Z.; Zhu, W.; Marken, F.; James, T.D. A redox-activated fluorescence switch based on a ferrocene-fluorophore-boronic ester conjugate. Chem. Commun. 2015, 51, 1293-1296. [CrossRef] [PubMed]

46. Magri, D.C.; Spiteri, J.C. Proof of principle of a three-input AND-INHIBIT-OR combinatorial logic gate array. Org. Biol. Chem. 2017, 15, 6706-6709. [CrossRef] [PubMed]

47. de Silva, A.P.; James, M.R.; McKinney, B.O.F.; Pears, D.A.; Weir, S.M. Molecular computational elements encode large populations of small objects. Nat. Mater. 2006, 5, 787-790. [CrossRef] [PubMed]

48. McKinney, B.O.F.; Daly, B.; Yao, C.; Schroeder, M.; de Silva, A.P. Consolidating molecular logic with new solid-bound YES and PASS 1 gates and their combinations. ChemPhysChem 2017, 18, 1760-1766. [CrossRef] [PubMed]

49. Vella Refalo, M.; Spiteri, J.C.; Magri, D.C. Covalent attachment of a fluorescent 'Pourbaix sensor' onto a polymer bead for sensing in water. New J. Chem. 2018. [CrossRef]

50. Brown, G.J.; de Silva, A.P.; James, M.R.; McKinney, B.O.F.; Pears, D.A.; Weir, S.M. Solid-bound, proton-driven, fluorescent 'off-on-off' switches based on PET (photoinduced electron transfer). Tetrahedron 2008, 64, 8301-8306. [CrossRef]

51. Tandon, R.; Luxami, V.; Kaur, H.; Tandon, N.; Paul, K. 1,8-Naphthalimide: A potent DNA intercalator and target for cancer therapy. Chem. Rec. 2017, 17, 956-993. [CrossRef] [PubMed]

52. Gellerman, G. Recent developments in the synthesis and applications of anticancer amonafide derivatives. A mini review. Lett. Drug Des. Discovery 2016, 13, 47-63. [CrossRef]

53. Wang, Y.; Hu, A. Carbon quantum dots: Synthesis, properties and applications. J. Mater. Chem. C 2014, 2, 6921-6939. [CrossRef]

54. Gong, X.; Liu, Y.; Yang, Z.; Shuang, S.; Zhang, Z.; Dong, C. An "on-off-on" fluorescent nanoprobe for recognition of chromium (VI) and ascorbic acid based on phosphorus/nitrogen dual-doped carbon quantum dot. Anal. Chim. Acta. 2017, 968, 85-96. [CrossRef] [PubMed]

(C) 2018 by the author. Licensee MDPI, Basel, Switzerland. This article is an open access article distributed under the terms and conditions of the Creative Commons Attribution (CC BY) license (http://creativecommons.org/licenses/by/4.0/). 